AC 2008-1207: ACCREDITATION OF ENGINEERING TECHNOLOGY ASSOCIATE DEGREE PROGRAMS

Warren Hill, Weber State University 


\title{
Accreditation of Engineering Technology Associate Degree Programs
}

\begin{abstract}
This paper discusses the issues involved with the accreditation of associate degree programs in Engineering Technology, and in particular looks at the concept of having differentiated criteria for such programs. The current Technology Accreditation Commission of ABET, Inc. criteria makes no distinction between associate degree and baccalaureate degree programs in the general criteria. The author would like to suggest some ways that the general criteria could be modified so as to have a different or modified set of criteria for associate degree programs as opposed to baccalaureate degree programs. This distinction becomes important in light of ABET being a signatory to the Sydney and Dublin accords which provide for the differences between and among technicians, technologists, and engineers.

\section{Background}

For the past two years the Technology Accreditation Commission of ABET, Inc. (TAC of ABET), the commission of ABET that accredits technology programs, has been discussing the development of differentiated accreditation criteria. The criteria for technology programs would be rewritten in such a way as to hold two year associate degree programs in technology to a different or modified set of criteria than would be applied to four year baccalaureate degree programs. The main impetus behind revising the criteria was the idea that two year programs simply cannot cover the same amount of material as four year programs and therefore should not be held to the same standards. This discussion takes on more importance because of ABET's consideration of becoming a signatory to the Dublin and Sydney accords. These accords will be discussed further on in this paper.

By way of background, the author served on the Technology Accreditation Commission for five years as a commissioner and most recently has completed his second year as an at-large member of the Executive Committee of TAC of ABET. As such, he has been directly involved with the discussions regarding the development of differentiated criteria and has supported efforts to develop such criteria.

The concept of differentiated criteria is not new to ABET. The Applied Science Accreditation Commission (ASAC) of ABET, Inc. has had differentiated criteria for many years. ASAC accredits programs in safety, industrial hygiene, health physics, environmental health \& safety, industrial or quality management, and surveying or geomatics. The way in which ASAC makes the distinction between associate degree and baccalaureate degree programs will also be discussed later in this paper.

In reviewing the 2008-2009 TAC of ABET criteria ${ }^{1}$ for technology programs, it became clear that there were at least two of the nine general criteria that would have to be modified if there were to be a viable differentiation between two year and four year degree programs. It was apparent to both the TAC Criteria Committee and the TAC Executive Committee that Criterion 3 which deals with program outcomes a-k, and Criterion 5 which deals with curriculum, would need to be changed. It also appeared that the remaining six general criteria could pretty much 
stay as they were and Criterion 9 dealing with program specific criteria, already makes allowance for associate degree programs versus baccalaureate degree programs.

The 2008-2009 Criteria currently contains in part the following language "Program outcomes are narrower statements that describe what students are expected to know and be able to do by the time of graduation. These relate to the skills, knowledge, and behaviors that students acquire in their matriculation through the program." As an example of why Criterion 3 as it currently exists would need to be changed to allow for differentiation between two and four year degree programs, it says that "Each program must demonstrate that graduates have.....an ability to apply creativity in the design of systems, components or processes appropriate to program objectives..." In the author's experience, very little design is done at the two year technician or associate degree level except for cookbook types of problems. For example in electronics technology, it is sometimes necessary to design a voltage divider which at a minimum consists of two resistors. Here some design is required in knowing what the load on the divider is, what the resistor ratios need to be, and what size of resistors are needed, both in ohms and in watts. However this type of design is far from the concept of "creativity" that would be expected from students in a four year degree program.

As an example of why Criterion 5 as it currently exists also should be changed to allow for differentiation between two and four year degree programs, the criterion currently contains in part the following language: "Algebra, trigonometry, and an introduction to mathematics above the level of algebra and trigonometry constitute the foundation mathematics for an associate degree program. Integral and differential calculus, or other appropriate mathematics above the level of algebra and trigonometry, constitutes the foundation mathematics for baccalaureate programs." While this language differentiates between associate and baccalaureate degree programs, it does so in a manner which does not give much guidance to associate degree programs in particular.

What constitutes mathematics above the level of algebra and trigonometry? Further what kind of algebra and trigonometry are they referring to, the kind that is usually called college algebra and is a prerequisite for calculus or the kind that is frequently called intermediate algebra and is equivalent to the second year of high school algebra? Or to confuse the issue even further, it is the kind of algebra and trigonometry that is taught in courses that are typically called technical math? It is this kind of lack of clarity that provides sufficient rationale to the desire to have differentiated criteria.

\section{Sydney and Dublin Accords}

These accords are international agreements that provide for recognition of graduates of accredited programs of each of the signatories by all of the other signatories to the accord. What is important about these accords in the context of this paper is that ABET is being requested to join these accords. Because these accords provide some fairly clear definitions regarding distinctions between engineers, technologists, and technicians, if ABET were to become a signatory, they would be agreeing in principle to abide by these definitions.

These definitions could serve as points of clarification in formulating differentiated criteria. For example, item $\mathrm{f}$ of the existing Criterion 3 states that "An engineering technology program must demonstrate that graduates have an ability to identify, analyze and solve technical problems." At the International Engineering Meeting ${ }^{2}$ (IEM) in 2003, a series of competency profiles were 
developed for each of the above professions. Two of the profiles dealt with the analysis of problems and the design and development of solutions to such problems. The differentiating characteristics that were applied to each of these professions for these two competencies were respectively the complexity of the analysis and the nature of the problem/uniqueness of the solution. The engineer is expected to be able to define, investigate, and analyze complex problems and then design or develop solutions to such problems. By contrast, the technologist is expected to identify, clarify, and analyze broadly defined problems and design or develop solutions to such problems. It is expected that the technician will identify, state and analyze broadly defined problems and design or develop solutions to such problems. The important thing to note here is the breath and depth to which each of these types of people are expected to go in analyzing and solving problems.

In contrast in some areas such as those listed in Criterion 3, items $\mathrm{g}$ and $\mathrm{i}$ which deal with communications and the understanding of professional, ethical and social responsibilities, the IEM makes no differentiation between engineers, technologists or technicians. For all of the people in these three groups, they are expected to communicate clearly with others and to conduct his or her activities ethically. Thus to be in agreement with these accords in these two categories, there would not need to be a change in Criterion 3 items $g$ and $i$ for either two year or four year programs.

\section{Applied Science Criteria}

The 2008-2009 ASAC of TAC criteria $^{3}$ differentiates between baccalaureate and associate degree programs primarily in Criterion 3, Program Outcomes. The program outcomes section states that:

A. Baccalaureate degree programs must demonstrate that graduates have:

(a) an ability to apply knowledge of mathematics, science, and applied sciences

(b) an ability to design and conduct experiments, as well as to analyze and interpret data

(c) an ability to formulate or design a system, process, or program to meet desired needs

(d) an ability to function on multidisciplinary teams

(e) an ability to identify and solve applied science problems

(f) an understanding of professional and ethical responsibility

(g) an ability to communicate effectively

(h) the broad education necessary to understand the impact of solutions in a global and societal context

(i) a recognition of the need for and an ability to engage in life-long learning

(j) a knowledge of contemporary issues

(k) an ability to use the techniques, skills, and modern scientific and technical tools necessary for professional practice.

B. Associate degree programs must demonstrate that graduates have:

(a) an ability to apply knowledge of mathematics, sciences, and other related disciplines

(b) an ability to conduct experiments, as well as to analyze and interpret data

(c) an ability to identify, formulate, and solve applied science problems

(d) an ability to function on teams 
(e) an understanding of professional and ethical responsibility

(f) an ability to communicate effectively

(g) a recognition of the need for and an ability to engage in life-long learning

(h) a knowledge of contemporary issues

(i) an ability to use the techniques, skills, and modern applied science tools necessary for professional practice

Note that these two sets of outcomes are different in both the number (baccalaureate degree programs are required to meet eleven criteria while associate degree programs only need to meet nine criteria) and in the depth of compliance. For example BS degree students are expected to both design and conduct experiments while AS degree students are to just expected to conduct experiments but are not expected to design them. As another example of depth of compliance, BS degree students are expected to function on multidisciplinary teams while AS degree students are just expected to have the ability to function on teams.

The two outcomes that BS students are expected to meet not required of AS degree students are the following: one, an ability to formulate or design a system, process, or program to meet desired needs and two, the broad education necessary to understand the impact of solutions in a global and societal context. Given that most AS degree programs typically require half the number of credits that are required for a BS degree, these two outcomes seem to be very appropriate for a BS degree but not for an AS degree.

It is also the author's opinion that the depth of knowledge in the area of contemporary issues is going to be less in an AS degree program than in a BS degree program, particularly if this knowledge if primarily obtained through the student's general education courses. A typical AS degree program requires only one third to one half of the general education credits of a BS degree program. This depth requirement is addressed somewhat through Criterion 5, section c, of the ASAC criteria which states that the "curriculum must include a general education component that complements the technical content of the curriculum and is consistent with the program and institution objectives." Thus the program can define its objectives such that they state what knowledge students are expected to have in the area of contemporary issues.

\section{Proposed TAC of ABET Approach}

Two possible approaches are currently under consideration to provide for differentiated criteria in the TAC of ABET criteria. The first deals with the program outcomes as described in Criterion 3, section a-k of the 2008-2009 criteria shown below.

a. an appropriate mastery of the knowledge, techniques, skills and modern tools of their disciplines,

b. an ability to apply current knowledge and adapt to emerging applications of mathematics, science, engineering and technology,

c. an ability to conduct, analyze and interpret experiments and apply experimental results to improve processes,

d. an ability to apply creativity in the design of systems, components or processes appropriate to program objectives,

e. an ability to function effectively on teams, 
f. an ability to identify, analyze and solve technical problems,

g. an ability to communicate effectively,

h. a recognition of the need for, and an ability to engage in lifelong learning,

i. an ability to understand professional, ethical and social responsibilities,

j. a respect for diversity and a knowledge of contemporary professional, societal and global issues, and

k. a commitment to quality, timeliness, and continuous improvement.

The first approach is to keep the same list of criteria as above but add some language that allows for differentiation between AS and BS degree programs. Suggested language for associate degree programs is that the program outcomes will define the depth and breath of knowledge and skill for engineering technicians and similar language is used for baccalaureate degree programs just replacing engineering technicians with engineering technologists. One of the difficulties with this proposal is that schools don't know necessarily what the depth and breath needs to be for the two different kinds of degrees program.

The other proposed approach suggests modifying the appropriate sections of Criterion 5 dealing with curriculum. For example, the section on communications could be written to include that "associate degree graduates will communicate effectively on well-defined engineering activities, will comprehend the work of others, will document their own work, and will give and receive clear instructions." On the other hand, "baccalaureate graduates will communicate effectively on broadly-defined engineering activities, will comprehend and write effective reports and design documentation, will make effective presentations, and will give and receive clear instructions." While this may be a workable solution, it appears to unnecessarily compliccate this Criterion.

\section{Alternate Proposal for Differentiated Criteria}

The author would like to propose an alternate set of criteria that takes into account the major differences between associate degree and baccalaureate degree programs. It further makes use of the format currently used by ASAC and includes the language from the Sydney and Dublin accords. The proposal would, as above, modify Criterion 3 and Criterion 5 as follows:

\section{Criterion 3. Program Outcomes}

For purposes of this section, broadly-defined activities are those that involve a variety of resources, that could require resolution between competing entities, that involve the use of new processes, materials, or techniques in innovative ways, and that require knowledge of standard operating procedures. Well-defined activities are those that involve limited resources, that could possibly require limited resolution, that involve the use of existing processes and materials in new ways, and that require a knowledge of basic operating processes.

A. Baccalaureate degree programs must demonstrate that graduates have the ability to:

a. select and apply appropriate techniques, resources, and modern engineering tools, including prediction and modeling, to broadly-defined engineering activities, with an understanding of the limitations,

b. apply knowledge of mathematics, science, engineering fundamentals and an engineering specialization to defined and applied engineering procedures, processes, systems or methodologies, 
c. conduct investigations of broadly-defined problems; locate, search and select relevant data from codes, databases and literature; and design and conduct experiments that provide valid conclusions,

d. design solutions for broadly-defined engineering technology problems and contribute to the design of systems, components or processes to meet specified needs with appropriate consideration for public health and safety, cultural, societal, and environmental considerations,

e. function effectively as an individual, and as a member or leader of diverse technical teams,

f. identify, formulate, and research the appropriate literature in order to solve broadlydefined engineering problems reaching substantiated conclusions using analytical tools appropriate to their discipline or area of specialization,

g. communicate effectively on broadly-defined engineering activities within the engineering community and with society at large, by being able to comprehend and write effective reports and design documentation, make effective presentations, and give and receive clear instructions,

h. recognize the need for, and have the ability to engage in independent on-going professional development,

i. understand and commit to professional ethics and responsibilities,

j. understand the impact of engineering solutions in a societal context and demonstrate knowledge of and need for sustainable development and

k. demonstrate an understanding of the societal, health, safety, legal and cultural issues and consequent responsibilities including a commitment to quality, timeliness, and continuous improvement.

B. Associate degree programs must demonstrate that graduates have:

a. apply appropriate techniques, resources, and modern engineering tools to welldefined engineering activities, with an awareness of the limitations,

b. apply knowledge of mathematics, science, engineering fundamentals and an engineering specialization to a wide range of practical procedures and practices,

c. identify, investigate, and solve well-defined problems through substantiated conclusions using codified methods within their discipline including an ability to locate and search relevant codes and catalogs and to conduct standard tests and measurements,

d. function effectively as an individual and as a member of a diverse technical teams,

e. identify and solve well-defined engineering problems reaching substantiated conclusions using codified methods of analysis specific to their field of activity,

f. communicate effectively on well-defined engineering activities with the engineering community by being able to comprehend the work of others, document their own work, and give and receive clear instructions,

g. recognize the need for, and have the ability to engage in independent on-going professional development,

h. understand and commit to professional ethics and responsibilities and

i. demonstrate a knowledge of the societal, health, safety, legal and cultural issues and the consequent responsibilities including a commitment to quality, timeliness, and continuous improvement. 


\section{Criterion 5. Curriculum}

The curriculum must appropriately and effectively develop these following subject areas in support of program outcomes and objectives.

a. Communications The communications content must develop the ability of graduates to:

(1) plan, organize, prepare, and deliver effective technical reports in written, oral, and other formats appropriate to the discipline and goals of the program

(2) incorporate communications skills throughout the technical content of the program

(3) utilize the appropriate technical literature and use it as a principal means of staying current in their chosen technology

b. Mathematics Associate degree programs will at a minimum include algebra and trigonometry at a level appropriate to the objectives of the program. Baccalaureate degree programs will at a minimum include integral and differential calculus or other mathematics above the level of level of algebra and trigonometry appropriate to the objectives of the program.

c. Physical and Natural Science The basic science content must include physics, chemistry, life science, or earth science in support of program educational objectives. This component must include laboratory experiences which develop expertise in experimentation, observation, measurement, and documentation.

d. Technical Content The technical content must develop the skills and knowledge appropriate to the goals of the program and must represent at least $1 / 3$ of the total credit hours but no more than $2 / 3$ the total credit hours for the program.

(1).The technical content of the curriculum consists of a technical core and the increasingly complex technical specialties found later in the curriculum. The technical core must provide the prerequisite foundation of knowledge necessary for the technical specialties.

(2).Laboratory activities must develop student competence in the use of analytical and measurement equipment common to the discipline and appropriate to the goals of the program.

(3). Technical courses must develop student knowledge and competence in the use of standard design practices, tools, techniques, and computer hardware and software appropriate to the discipline and goals of the program.

(4). Baccalaureate degree programs must also provide a capstone or other kinds of integrating experiences based upon the cumulative knowledge and skills acquired in earlier course work.

Cooperative Education Cooperative education credit used to satisfy prescribed elements of these criteria must include an appropriate academic component evaluated by the program faculty.

There are several things to note about these proposed criteria. The first is that associate and baccalaureate degree programs are differentiated by having students in the former working on well-defined problems whereas students in the latter are working on broadly-defined problems. A second difference is that the number of outcomes for the associate degree has been reduced to 
nine as opposed to the eleven that are required by the baccalaureate degree. This is the same number for each type of degree currently required by the ASAC criteria. Finally, Criterion 5 dealing with curriculum has been simplified and hopefully clarified.

Some of the specific differences in Criterion 5 as they apply to associate degree programs include in the section on mathematics where it states algebra and trigonometry are required but nothing beyond those two subjects. Another difference is that the requirement for a capstone experience has been eliminated for associate degree programs. The rationale behind all of these modifications is to provide a realistic set of criteria for associate degree programs.

Summary

These proposed changes only describe a small portion of the current discussion that is currently taking place in TAC regarding differentiated criteria. In the author's opinion, there is much discussion yet to take place. However, it appears that the ASAC criteria seems to have found a good middle ground by having two different sets of program outcomes for the two different types of degrees. Coupling this approach with an appropriate revision of Criterion 5 of the 20082009 TAC criteria would seem to be a good compromise and is the approach taken by the author in his alternative proposal. TAC of ABET is very interested in hearing what two year schools in particular have to say about these proposed revisions. Comments can be sent to the author at the following e-mail address: whill@weber.edu.

Bibliography

1. Criteria for Accrediting Engineering Technology Programs, Technology Accreditation Commission of ABET, Inc., Incorporates all changes approved by the ABET Board of Directors as of November 3, 2007.

2. Graduate Attributes and Professional Competencies, Engineers Mobility Forum, Engineering Technologists Mobility Forum, Ver 1.1 - 13 June 2005.

3. Criteria for Accrediting Applied Science Programs, Applied Science Accreditation Commission of ABET, Inc., Incorporates all changes approved by the ABET Board of Directors as of November 3, 2007. 